\section{MS30-P25 Structure and activity study of gold(I) catalysts in the presence of thiols and amines}

Georgina M. Rosair ${ }^{1}$, Ai-Lan Lee ${ }^{1}$, Paul C. Young ${ }^{1}$, Samantha L. Green $^{1}$

1. Institute of Chemical Sciences, Heriot-Watt University, Edinburgh, EH14 4AS, United Kingdom

email: g.m.rosair@hw.ac.uk

Homogenous Gold catalysis has evolved from the rare and unusual to a rapidly evolving area of research. Gold catalysts act as $\pi$-Lewis acids for activating C-C $\pi$ bonds but it is their capacity for fine tuning to control the selectivity and activity of reactions as well as their ready availability and robustness to oxygen that makes gold catalysts shine ${ }^{1}$.

This work describes the quest to find the identity and activity of gold species present in gold catalysed reactions with cyclopropenes, allenes and allylic alcohols. A range of common nucleophiles, namely alcohols, thiols and amines have been employed in these reactions. Yet the presence of these nucleophiles could dramatically alter both selectivity and reactivity of the gold catalyst. Therefore we needed to identify the gold species present in these reactions to understand what was happening ${ }^{2}$.

A pattern emerged of nucleophilicity and gold centre nuclearity in the degree of activity and identity of the gold species in these gold catalysed reactions.

1.M. Jia and M. Bandini, ACS Catal. 2015, 5, $1638-1652$

2.P. C. Young, S.L.J. Green, G.M.Rosair and A-L. Lee, Dalton Trans., 2013, 42, 9645

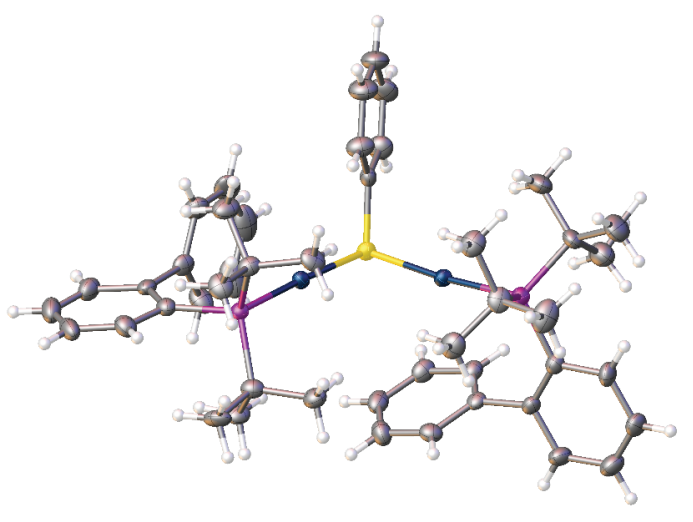

Figure 1. Gold complex in the presence of thiols. Counterion omitted for clarity

Keywords: gold catalysis, activity, nucleophile

\section{MS30-P26 A heterometallic oxalate compound with square $\left\{\mathrm{Cr}_{2} \mathrm{Nb}_{2}(\mu-\mathrm{O})_{4}\right\}$ core as precursor for mixed oxide \\ Marijana Jurić ${ }^{1}$, Lidija Androš Dubraja ${ }^{1}$, Jasminka Popović ${ }^{1}$}

1. Ruđer Bošković Institute, Bijenička cesta 54, 10000 Zagreb, Croatia

email: Marijana.Juric@irb.hr

Recent research related to the multicomponent $\mathrm{Nb}$-containing oxide materials revealed their very appealing structural and physical properties, leading to their development for a wide range of technological applications, such as ferroelectric and piezoelectric materials, ion conductors, and also as promising catalysts in several highly challenging processes. ${ }^{[1]}$ Lately, metal-organic coordination systems have been used as single-source precursors for the preparation of mixed-metal oxides through thermal decomposition. This method, compared with conventional methods, has several advantages: $(i)$ the obtained material is more homogeneous because the metals are mixed at the molecular level; (ii) the resulting materials have relatively high specific surface areas because the oxides are formed under significantly milder conditions; (iii) there is much greater control of the metal stoichiometry in the final products; and (iv) there are no long-term and repeated grinding procedures. The oxalate anion, $\mathrm{C}_{2} \mathrm{O}_{4}{ }^{2-}$ easily decomposes to the vapor phases $\mathrm{CO}_{2}$ and $\mathrm{CO}^{2}$, through the low-temperature routes, and hence, the heterometallic oxalate-based compounds are suitable for the use as molecular precursors for mixed oxides.$^{[1-3]}$

Hence, due to the growing need for Nb-based oxides, further investigation of the $\mathrm{Nb}$-containing heterometallic oxalate compounds that could serve as single-source precursors is of great importance. As a continuation of our studies, ${ }^{[1-3]}$ novel compound $\left[\mathrm{Cr}(\mathrm{bpy})_{2}(\mu-\mathrm{O})_{2} \mathrm{Nb}\left(\mathrm{C}_{2} \mathrm{O}_{4}\right)_{2}\right]_{2} \cdot 3 \mathrm{H}_{2} \mathrm{O}$ (1) (bpy = 2,2'-bipyridine) was synthesized and characterized by single-crystal X-ray diffraction, IR and UV/Vis spectroscopy and thermal analysis. The molecular structure of 1 exhibits a square shaped $\left\{\mathrm{Cr}_{2} \mathrm{Nb}_{2}(\mu-\mathrm{O})_{4}\right\}$ core in which oxo-bridged $\mathrm{Cr}^{3+}$ and $\mathrm{Nb}^{5+}$ ions reside in alternate corners (Figure 1). Both metal ions display the octahedral coordination geometry. Thermal treatment of $\mathbf{1}$ at $1000{ }^{\circ} \mathrm{C}$ leads to molecular precursor-to-material conversion that yields the mixed-metal $\mathrm{CrNbO}_{4}$ oxide, explored by powder X-ray diffraction.

[1] M. Jurić, J. Popović, A. Šantić, K. Molčanov, N. Brničević, P. Planinić, Inorg. Chem., 2013, 52, 1832-1842; [2] L. Androš, M. Jurić, J. Popović, A. Šantić, P. Lazić, M. Benčina, M. Valant, N. Brničević, P. Planinić, Inorg. Chem., 2013, 52, 14299-14308; [3] J. Habjanič, M. Jurić, J. Popović, K. Molčanov, D. Pajić, Inorg. Chem., 2014, 53, 9633-9643. 